NASA/TM-1998-206615

\title{
Status and Design Concepts for the Hydrogen On-Orbit Storage and Supply Experiment
}

David J. Chato

Lewis Research Center, Cleveland, Ohio

Melissa Van Dyke

Marshall Space Flight Center, Alabama

J. Clair Batty and Scott Schick

Utah State University, North Logan, Utah

Prepared for the

Space Technology and Applications International Forum cosponsored by NASA, SNL, DOE, and USAF

Albuquerque, New Mexico

National Aeronautics and

Space Administration

Lewis Research Center 
This report contains preliminary findings, subject to revision as analysis proceeds.

Available from

NASA Center for Aerospace Information 800 Elkridge Landing Road

Linthicum Heights, MD 21090-2934

Price Code: A03
National Technical Information Service 5287 Port Royal Road Springfield, VA 22100

Price Code: A03 


\title{
STATUS AND DESIGN CONCEPTS FOR THE HYDROGEN ON-ORBIT STORAGE AND SUPPLY EXPERIMENT
}

\author{
David J. Chato \\ NASA Lewis Research Center \\ Mail Stop 60-4 \\ 21000 Brookpark Road \\ Cleveland, $\mathrm{OH}, 44135$ \\ (216) $977-7488$
}

\author{
Melissa Van Dyke \\ NASA Marshall Space Flight \\ Center \\ Mail Code EP25 \\ Marshall Space Flight Center, \\ $\mathrm{AL}, 35812$ \\ (205) $544-5720$
}

\author{
J. Clair Batty and Scott Schick \\ Space Dynamics Laboratory, \\ Utah State University \\ 1695 North Research Park Way \\ UMC 9700 \\ North Logan, UT 84341 \\ (435)797-2866 and 797-4426
}

\begin{abstract}
$\underline{\text { Abstract }}$
This paper studies concepts for the Hydrogen On-Orbit Storage And Supply Experiment (HOSS). HOSS is a space flight experiment whose objectives are: Show stable gas supply for storage and direct gain solar-thermal thruster designs; and evaluate and compare low-g performance of active and passive pressure control via a thermodynamic vent system (TVS) suitable for solar-thermal upper stages. This paper shows that the necessary experimental equipment for HOSS can be accommodated in a small hydrogen dewar of 36 to 80 liter. Thermal designs for these dewars which meet the on-orbit storage requirements can be achieved. Furthermore ground hold insulation and shielding concepts are achieved which enable storing initially subcooled liquid hydrogen in these small dewars without venting in excess of 144 hours.
\end{abstract}

\section{INTRODUCTION}

Recently, there has been significant interest in Solar-Thermal rocketry (using concentrated sunlight instead of combustion to heat and expand gases for rocket propulsion). There are on-going programs for Solar Thermal rockets in industry (Cady 1996a), Department of Defense (DoD)(Cady 1996b and Jacox 1996), and the National Aeronautics and Space Administration (NASA). Hydrogen is the propellant of choice for solar-thermal rockets due to its high specific impulse. Hydrogen is stored most efficiently as a cryogenic liquid.

NASA has been studying technologies for the management of cryogenic fluids in low gravity for many years. Looking at the cryogenic fluid management technologies for solar thermal stages, the key issues are controlled propellant acquisition and long term storage (Chato 1997). Recent solar-thermal design concepts (Cady 1996a, Cady 1996b, Jacox 1996) have combined these functions into a single system which uses a thermodynamic vent system to remove energy from the liquid storage and provide propellant to the solar thermal collector. Although TVS systems have been studied extensively, they have not been proven in space and it is felt that the change in fluid configuration (see Bentz 1993 for a discussion of zero-g mixing flow patterns) could have a significant effect on their performance. Ground testing with feed system components show that for this coupled system start transients may affect predicted performance. The solarthermal rocket is sensitive to transient issues because firing occurs in many short bursts and because the vent and feed systems are coupled. Space testing is necessary because of TVS sensitivity to low gravity and the difficulty in simulating the hard vacuum of space while outflowing hydrogen.

\section{EXPERIMENT CONCEPT}

The authors have undertaken the design of a small scale experimental spacecraft to investigate these issues. This spacecraft has been named Hydrogen On-Orbit Storage And Supply Experiment (HOSS). Details of the design concept are given in Chato (1997). Key objectives and design features are summarized below.

\section{Objectives}

The objectives of this experiment will be:

- Show stable gas supply (steady flow rate, minimal liquid, over an extended period) for storage and direct gain solarthermal thruster designs. 
- Evaluate and compare low-g performance of active and passive pressure control via thermodynamic vent system (TVS) suitable for solar-thermal upper stages.

\section{Approach}

The experiment design concept will:

- Launch a small (36-80 liter) hydrogen dewar with liquid acquisition device (LAD), mixer and TVS.

- Operate dewar through several regimes (including short burst transient operation) of active and passive pressure control while monitoring hydrogen flow rates, quality and quantities.

- Scale outflow to match solar-thermal flow rate requirements.

- Verify that liquid free gas is supplied to the overboard vent (the vent simulates the solar-thermal thruster)

\section{DESIGN STUDIES}

Chato (1997) established the baseline requirements for HOSS. It became evident, from these requirements that the key element of the spacecraft is the liquid hydrogen dewar. Its weight dominates the spacecraft weight. Its thermal performance determines ground hold capability and the complexity of ground operations. To start the design effort, hardware similar to existing pieces was baselined, including the radiometer dewar built for the Shuttle Pallet Satellite III (SPAS) experiment (unpublished), the LAD from Bentz (1993), and the heat exchanger-mixer assembly from Seigneur (1994). It was clear from our previous work that a 36 liter dewar similar to SPAS would not be capable of storing hydrogen for 30 days (the typical solar-thermal mission) so a larger 80 liter design study was also conducted. The effort was concentrated on two key areas. The first area is mounting existing NASA hardware in the 36 and 80 liter vessel, and defining support structures, valving, plumbing, and mass. The second area considered thermal performance of the dewar system and what ground handling constraints this imposed.

\section{Dewar Design}

The first step was to look at a 80 liter dewar design. This design, as shown in figure 1, has an inner vessel $40.6 \mathrm{~cm}$ diameter by $72.2 \mathrm{~cm}$ long and overall dewar size of $54.9 \mathrm{~cm}$ diameter by $94.8 \mathrm{~cm}$ long. This design will hold $5.7 \mathrm{~kg}$ of hydrogen. The vacuum jacket is made of aluminum. The hydrogen tank, liquid nitrogen guard tank, valves, plumbing and fittings are made of stainless steel. There is a removable lid on the inner vessel to allow access to the mixer, LAD, and heat exchanger. The lid is sealed with a bolted metal seal. Another bolt flange on the vacuum jacket allows access to this lid as well as the internal plumbing. Valves for the panel layout were chosen because of prior use on other programs. Valves include tank fill and vent, liquid nitrogen fill and vent, helium fill and vent, and a TVS valve assembly (described below) as well as an evacuation port for the vacuum jacket. The TVS assembly includes a pyro valve to seal the TVS during ground operation, a solenoid valve to control the TVS operation, a relief valve to protect against dewar overpressure on-orbit, and a tee to vent the TVS flow without thrusting. The NASA heat exchanger has been modified to allow a mixer motor to sit within it thereby greatly reducing the overall length. The design also substitutes an available shorter NASA mixer for the mixer used by Seigner(1994). The dry weight of the 80 liter dewar is estimated at $91.6 \mathrm{~kg}$

The hydrogen tank is insulated using evacuated multi-layer insulation (MLI) and supported using three nested G10 fiberglass tubes. A toroidal tank is attached at the intersection of the outer two tubes. This tank will be filled with liquid nitrogen on the ground to limit heat entering the hydrogen. This technique allows the dewar to remain filled with liquid hydrogen for long periods of time without venting. The liquid nitrogen will be vented prior to launch. A coil of tubing is attached to the inner vessel to allow the liquid hydrogen to be subcooled by flowing liquid helium around the hydrogen tank. This again extends the ground hold capabilities of the tank and provides a means of reducing tank pressure quickly without venting. 


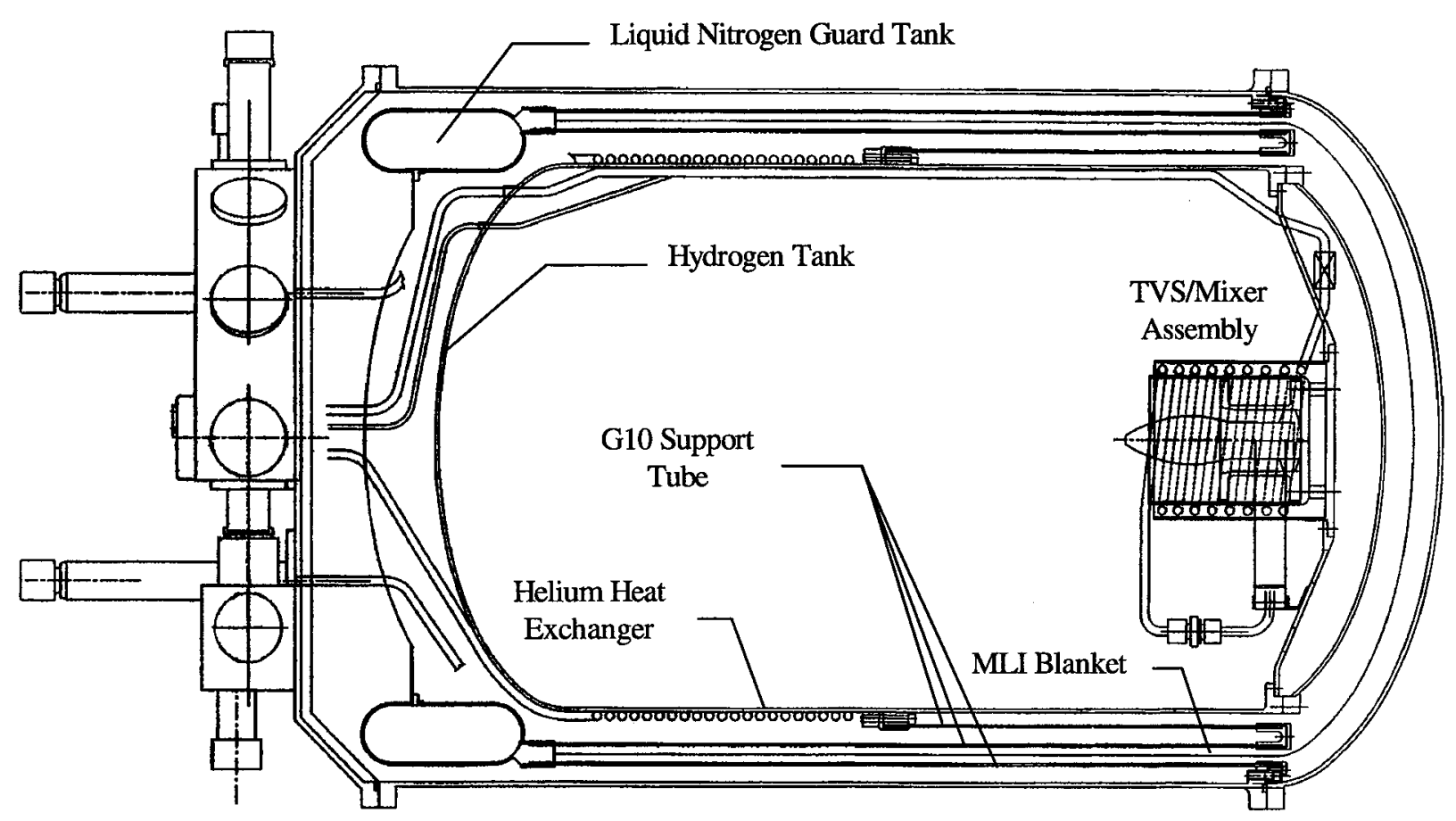

a) Side View

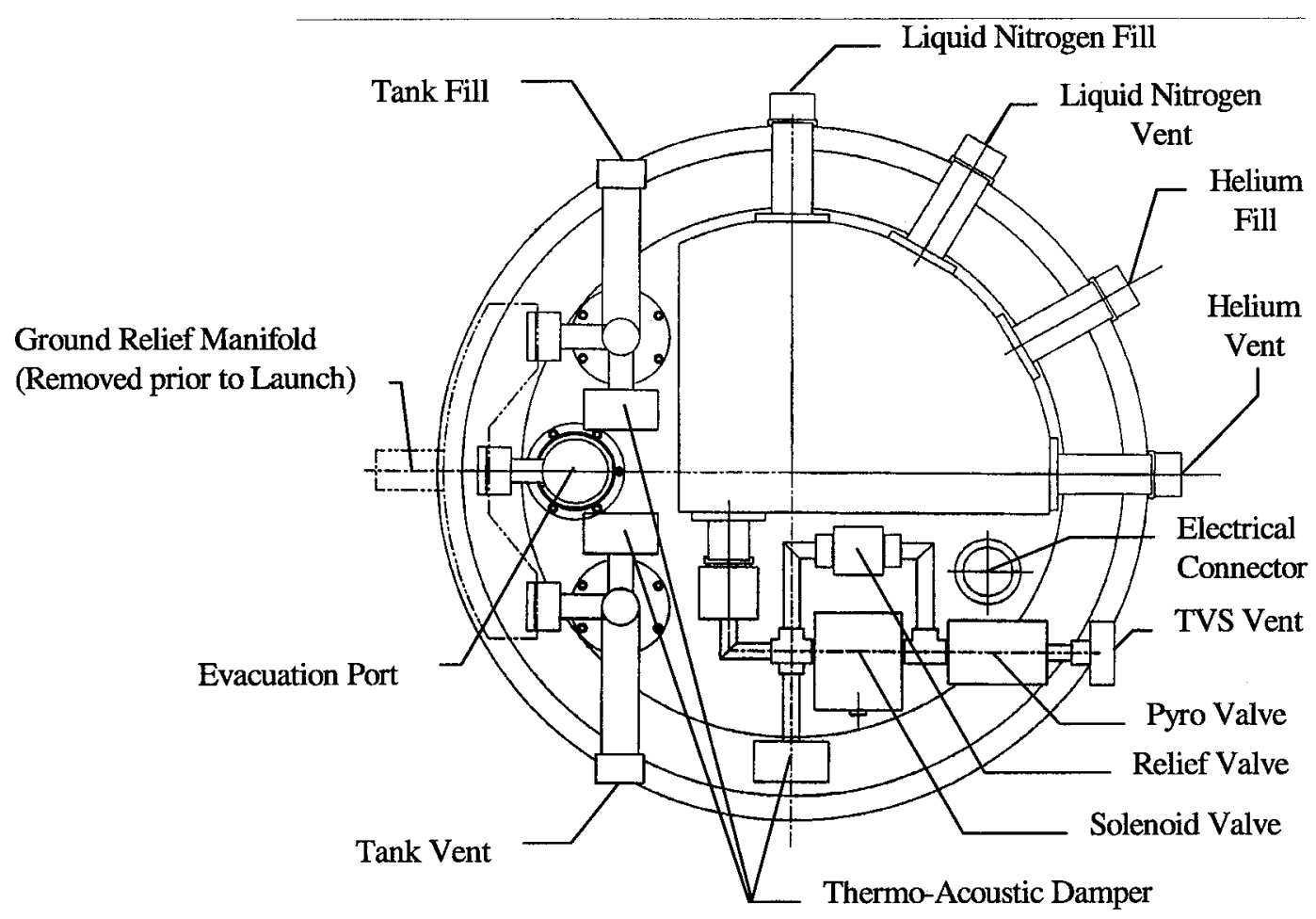

b) Top View

FIGURE 1. 80 Liter Dewar Layout.

A revised 36 liter dewar design, incorporating the design features of the 80 liter dewar was also completed. It was felt that a smaller dewar size and mass might decrease launch costs and this might be more important than storage time. This dewar holds $2.52 \mathrm{~kg}$ of hydrogen and has a dry mass of $58.6 \mathrm{~kg}$ (only $35 \%$ less than the 80 liter dewar). Overall size is $38.4 \mathrm{~cm}$ diameter $71.6 \mathrm{~cm}$ long. One reason that the masses are close is that the external plumbing is identical. The smaller space available on the 36 liter dewar necessitates the use of a stepped vacuum shell lid to achieve the required mounting space. 
Results of the design study indicate both dewars are feasible. There is a preference for the 80 liter dewar since the greater volume will make achievement of the experimental objectives easier, and the weight difference between the two designs is not that great. Both designs will be carried forward until spacecraft designs and launch vehicle selection is complete. Volume constraints may yet dictate use of the smaller dewar.

\section{Insulation Designs}

Heat load estimates were by computer (SINDA) using a simple lumped element thermal model for each dewar. Heat loads to the hydrogen tank are shown in table 1.

Table 1 Heat Loads on Hydrogen Tank (Watts)

\begin{tabular}{|l|l|l|}
\hline & 80 Liter Dewar & 36 Liter Dewar \\
\hline Supports & 0.458 & 0.443 \\
\hline MLI & 0.752 & 0.539 \\
\hline Plumbing & 0.299 & 0.296 \\
\hline Wires & 0.0007 & 0.0007 \\
\hline Pressure Sensor Lines & 0.144 & 0.144 \\
\hline Total & 1.66 & 1.42 \\
\hline
\end{tabular}

The nominal heat load on the 80 liter dewar with this design is $1.66 \mathrm{~W}$ (at a $300 \mathrm{~K}$ shell temperature) resulting in an onorbit storage time of 18 days. If the shell temperature can be reduced to $250 \mathrm{~K}$ the heat load is reduced to $0.985 \mathrm{~W}$ and the on-orbit storage time will the meet 30 day storage objectives. A $250 \mathrm{~K}$ shell temperature could be achieved by the common techniques of using the spacecraft solar arrays to shadow the dewar or coating the tank with specially reflective surfaces (such as silver-Teflon film). Nominal heat load on the 36 liter dewar is $1.42 \mathrm{~W}$ resulting in a 9 day orbit life, although this can be increased to 15 days by lowering the shell temperature as described previously. Another source of heat that can be eliminated is the $0.144 \mathrm{w}$ due to pressure sensor lines. The baseline design specified pressure sensors external to the vacuum space with tubes leading from the inner vessel. These may be replaced by temperature compensated sensors which can be mounted on the inner vessel wall, therefore eliminating the need for long tubes and their associated heat leak.

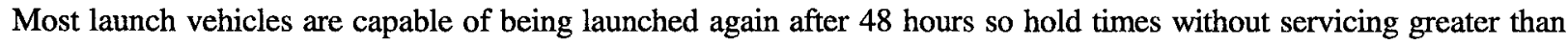
this are desirable. Ground hold for these insulations without the liquid nitrogen guard was less than desired. For the 36 liter tank the time to rise from the loading temperature of $20 \mathrm{~K}$ to $25 \mathrm{~K}$ (saturation pressure of 2,466 torr) is 21 hours. For the 80 liter dewar this time is 42 hours.

The first approach to improving ground hold was the addition of a liquid helium subcooling coil. This coil serves several purposes. Prior to loading hydrogen this coil will be used to cool the tank down to $20 \mathrm{~K}$ thus eliminating the hydrogen needed for tank chilldown. Periodically after fill liquid helium will be circulated to reduce the liquid hydrogen temperature to $14 \mathrm{~K}$ pulling the tank pressure down correspondingly to 52 torr. From $14 \mathrm{~K}$ the hold time to $25 \mathrm{~K}$ increased to 48 hours for the 361 dewar and 96 hours for the 801 dewar.

With the previously described liquid nitrogen guard tank added to the system hold times are substantially increased. The toriodal tank is filled with enough liquid nitrogen to hold for 48 hours. During this time period heat leak into the tank is absorbed by boiling nitrogen and the net heat leak into the liquid hydrogen is greatly reduced. Assuming the guard tank is allowed to boil dry the hold time for the 361 dewar is over 144 hours and over 168 hours for the 80 liter dewar. If the guard tank is periodically refilled the hold time is extended greatly.

Tank temperature rise rates with all systems in place are shown in figures 2 and 3 . The curves show a shallow rise in temperature until the liquid nitrogen tank is depleted at 48 hours followed by a steeper increase afterwards. Also shown are the liquid nitrogen tank temperature which is constant until the liquid nitrogen is depleted then rises rapidly, and the temperature of the joint of the folded tubes closest to the tank which is constant when the liquid nitrogen is present but afterwards slowly rises in temperature. 


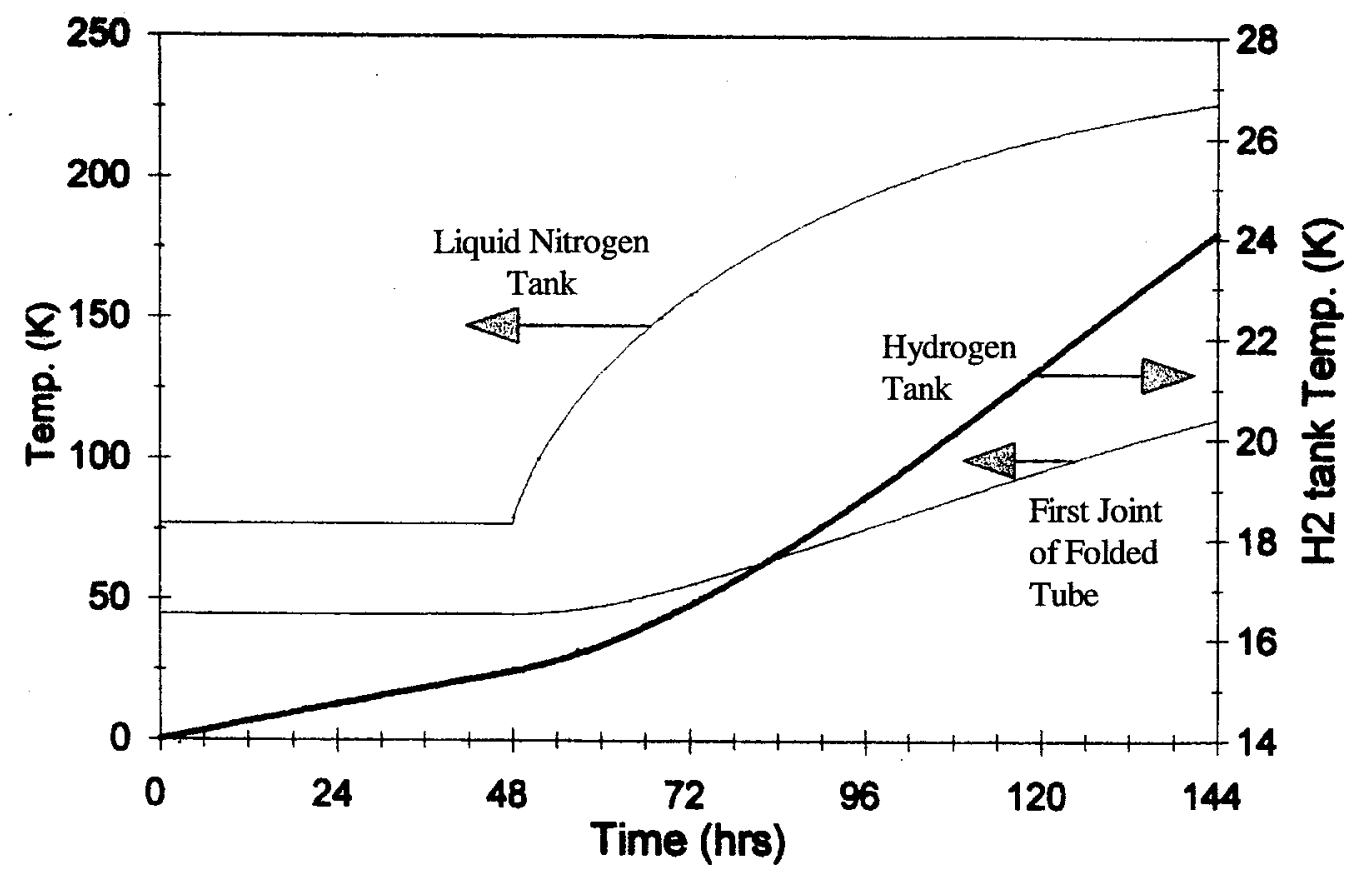

FIGURE 2. 36 Liter HOSS Ground Hold with $\mathrm{LN}_{2}$ Tank

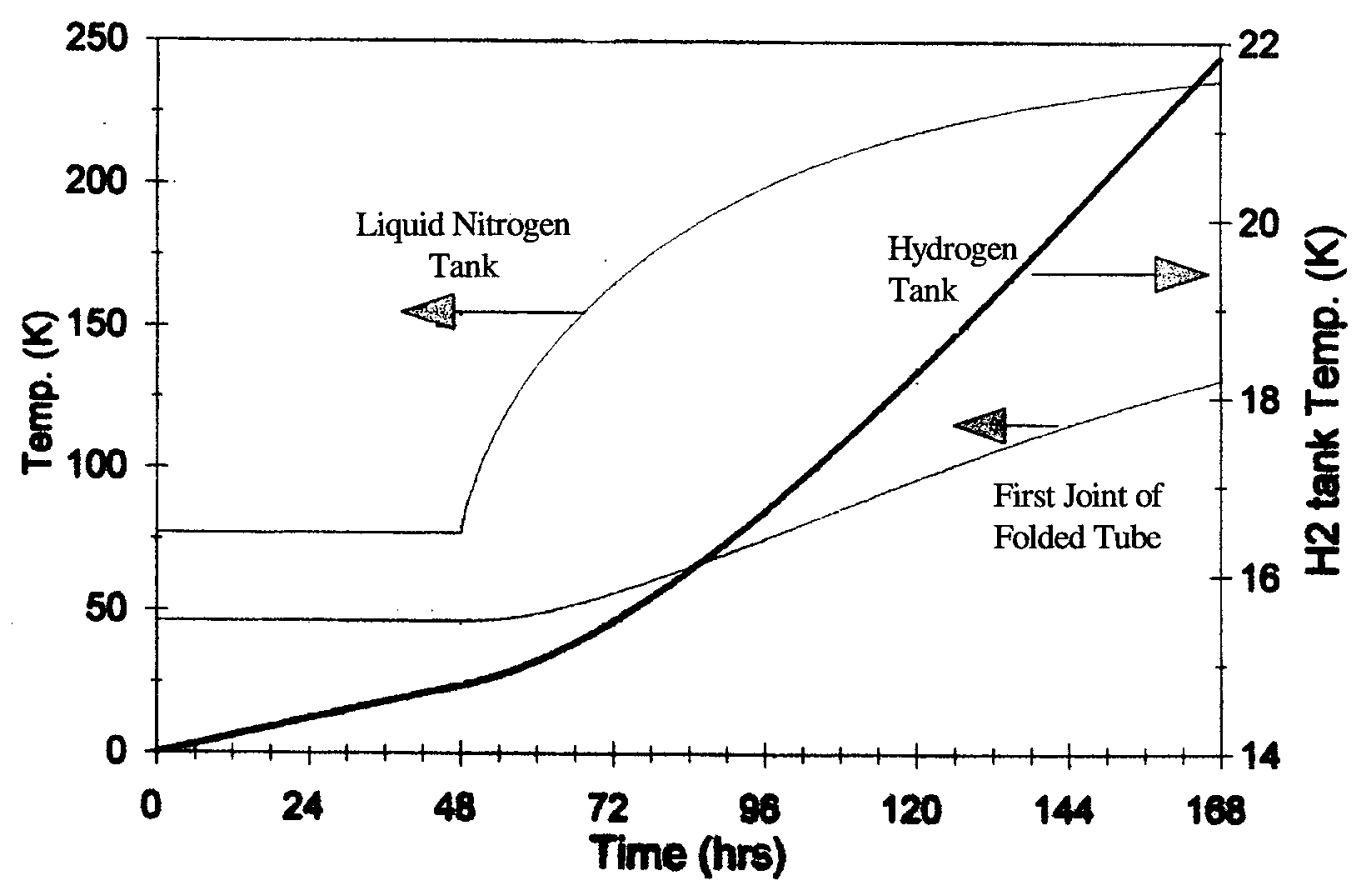

FIGURE 3. 80 Liter HOSS Ground Hold with $\mathrm{LN}_{2}$ Tank.

\section{Other Design Studies}

Launch vehicle and spacecraft bus selection studies are on-going. Results of these efforts will be reported in the future. Other design trades were conducted with regard to ground handling and spacecraft mission. Since these trades are closely tied to launch vehicle selection and spacecraft bus design, results are very preliminary. Key results of the ground handling trade indicate that Government Owned equipment from the Wide Field Infrared Explorer (WIRE) satellite 
(unpublished) may be very useful. Steps are being taken to borrow this equipment for HOSS. Vandenburg Air Force was tentatively selected as the baseline launch site since facilities for handling small hydrogen payloads exist from the Midcourse Space Experiment (MSX; Smola 1996) and WIRE (to be launched shortly on a Pegasus rocket) programs. Spacecraft mission designs confirmed the viability of the sun-synchronous orbit, and one-a-day data download approaches suggested in Chato 1997, but indicate that other approaches may offer benefits also. Discussions with small satellite vendors indicated that HOSS is heavier than most small spacecraft, but also indicated a scale up of their existing design was very feasible.

\section{CONCLUSIONS}

This design effort shows that the necessary experimental equipment for HOSS can be accommodated in a small 36 to 80 liter hydrogen dewar and meet all the experiment objectives. Thermal designs for these dewars which meet the onorbit storage requirements can be achieved. Furthermore, the study has shown that there are insulation and guard techniques for ground processing capable of storing liquid hydrogen in these small dewars without venting in excess of 144 hours. Other areas can now be detailed. Design studies underway include selection of suitable low cost launch vehicles and integration of the dewar design into a satellite bus. These efforts bring the flight of the HOSS experiment inexorably closer.

\section{Acknowledgments}

The authors wish to thank: The Utah State Team for their hard work and effort. NASA Marshall's' Preliminary Design Office for their spacecraft study. Orbital Sciences Corporation and Spectrum Astro Incorporated for their patience and assistance.

\section{$\underline{\text { References }}$}

Bentz, M. D., R. H. Knoll, M. M. Hasan, and C. S. Lin (1993) "Low-G Fluid Mixing: Further Results from the Tank Pressure Control Experiment," American Institute of Aeronautics and Astronautics, Reston, VA, AIAA Paper 932423, June 1993.

Cady, E. and A. Olsen Jr. (1996a) "Solar Thermal Upper Stage Technology Demonstrator Program," American Institute of Aeronautics and Astronautics, Reston, VA, AIAA Paper 96-3011, July 1996.

Cady, E. and A. Olsen Jr. (1996b) "Cryogen Storage and Propellant Feed System for the Integrated Solar Upper Stage (ISUS) Program," American Institute of Aeronautics and Astronautics, Reston, VA, AIAA Paper 96-3044, July 1996.

Chato, D. J. and , L. Hastings (1997) "An Experiment to Demonstrate Key Cryogenic Technologies for Solar Thermal Rockets," Space Technology and Applications International Forum (STAIF 97), American Institute of Physics, CONF 970115, M. S. El-Genk, ed, AIP Conf. Proc. No. 387, 1:517-522.

Jacox, M. G., F. G. Kennedy, J. Malloy, C. Merk ,and T. M. Miller (1996) "Integrated Solar Upper Stage (ISUS) Space Demonstration System Definition Study" Phillips Laboratory, Kirtland AFB, NM January, 1996. PL-TR-96-1006.

Seigneur, A. (1994) "Design, Analysis, Fabrication and Testing of an Active Heat Exchanger for Use in Cryogenic Fluids," Masters Thesis, Cleveland State University, March 1994.

Smola, James F. et al (1996) "MSX Ground Operations," John Hopkins APL Technical Digest, Vol 17, No 2, April 1996. 
Public reporting burden for this collection of information is estimated to average 1 hour per response, including the time for reviewing instructions, searching existing data sources, gathering and maintaining the data needed, and completing and reviewing the collection of information. Send comments regarding this burden estimate or any other aspect of this collection of information, including suggestions for reducing this burden, to Washington Headquarters Services, Directorate for Information Operations and Reports, 1215 Jefferson Davis Highway, Suite 1204, Arlington, VA 22202-4302, and to the Office of Management and Budget, Paperwork Reduction Project (0704-0188), Washington, DC 20503.

\begin{tabular}{|l|l|l|}
\hline 1. AGENCY USE ONLY (Leave blank) & 2. REPORT DATE & 3. REPORT TYPE AND DATES COVERED
\end{tabular}

\begin{tabular}{|l|l|l}
\hline & January 1998 & Technical Memorandum \\
\hline
\end{tabular}

\section{TITLE AND SUBTITLE}

5. FUNDING NUMBERS

Status and Design Concepts for the Hydrogen On-Orbit Storage and Supply Experiment

6. AUTHOR(S)

WU-953-73-00-00

David J. Chato, Melissa Van Dyke, J. Clair Batty, and Scott Schick

7. PERFORMING ORGANIZATION NAME(S) AND ADDRESS(ES)

National Aeronautics and Space Administration

Lewis Research Center

Cleveland, Ohio 44135-3191

8. PERFORMING ORGANIZATION REPORT NUMBER

E-11035

9. SPONSORING/MONITORING AGENCY NAME(S) AND ADDRESS(ES)

National Aeronautics and Space Administration

Washington, DC 20546-0001

10. SPONSORING/MONITORING AGENCY REPORT NUMBER

NASA TM-1998-206615

\section{SUPPLEMENTARY NOTES}

Prepared for the Space Technology and Applications International Forum cosponsored by NASA, SNL, DOE, and USAF, Albuquerque, New Mexico, January 25-29, 1998. David J. Chato, NASA Lewis Research Center; Melissa Van Dyke, NASA Marshall Space Flight Center, Alabama 35812; J. Clair Batty and Scott Schick, Utah State University, North Logan, Utah 84341. Responsible person, David J. Chato, organization code 5870, (216) 977-7488.

12a. DISTRIBUTION/AVAILABILITY STATEMENT

12b. DISTRIBUTION CODE

Unclassified - Unlimited

Subject Category: 34

Distribution: Nonstandard

This publication is available from the NASA Center for AeroSpace Information, (301) 621-0390.

13. ABSTRACT (Maximum 200 words)

This paper studies concepts for the Hydrogen On-Orbit Storage and Supply Experiment (HOSS). HOSS is a space flight experiment whose objectives are: Show stable gas supply for storage and direct gain solar-thermal thruster designs; and evaluate and compare low-g performance of active and passive pressure control via a thermodynamic vent system (TVS) suitable for solar-thermal upper stages. This paper shows that the necessary experimental equipment for HOSS can be accommodated in a small hydrogen dewar of 36 to 80 liter. Thermal designs for these dewars which meet the on-orbit storage requirements can be achieved. Furthermore ground hold insulation and shielding concepts are achieved which enable storing initially subcooled liquid hydrogen in these small dewars without venting in excess of 144 hours.

14. SUBJECT TERMS

\begin{tabular}{|l|l|}
\hline & $\begin{array}{c}\text { 15. NUMBER OF PAGES } \\
12\end{array}$ \\
\cline { 2 - 2 } & $\begin{array}{c}\text { 16. PRICE CODE } \\
\text { A03 }\end{array}$ \\
\hline $\begin{array}{l}\text { 19. SECURITY CLASSIFICATION } \\
\text { OF ABSTRACT } \\
\text { Unclassified }\end{array}$ & 20. LIMITATION OF ABSTRACT \\
\hline
\end{tabular}

NSN 7540-01-280-5500

Standard Form 298 (Rev. 2-89)

Prescribed by ANSI Std. Z39-18 298-102 
